\title{
Preface to Special Issue on Rare Earth Catalysis
}

Rare earth elements have wide applications in optics, electronics, magnetics, and catalysis due to the unique properties of $4 f$ electrons. Many countries see them as having strategic values and consider them a "vault for new materials". China has abundant reserves of rare earth elements and produces most of the world's supplies. With the quick development of the metal alloy, magnet, and fluorescent powder industries, there have been large usages of the middle and heavy rare earth metals, resulting in a large backlog of the light rare earth oxides (La, Ce, etc.). The research and development of rare earth catalytic materials will greatly promote the highly efficient use of these abundant rare earth elements, such as La and Ce.

Rare earth elements exhibit special chemical properties because of the non-full $4 f$ orbitals and lanthanide contraction. Rare earths can be used as the active component and support of catalysts for many important chemical processes in the petrochemical industry, automotive emission control, catalytic combustion of VOCs and fossil fuels, and in fuel cells. With the development of new energy sources for a more sustainable world, rare earth catalysis has flourished in recent years. Much research has shown that Ce acts as an "electron reservoir" to store up the free electrons left in formed oxygen vacancies, and La effectively alters the acidity of zeolites and improves their structural stability. Advances in nanotechnology have helped us design and prepare nanoscopic and hybrid rare earth catalytic materials. Developments in theoretical calculations give us opportunities to understand rare earth catalysis at the atomic level. To show recent progress in rare earth catalysis research, we are pleased to have been able to invite some scientists to present their excellent work and share their viewpoints on rare earth catalysis in this special issue.

This special issue on rare earth catalysis includes environmental catalysis, organic catalysis, energy catalysis, and density functional theory studies, and consists of 2 reviews, 1 communication, and 13 articles. The review papers introduced the application of ceria for the SCR of $\mathrm{NO}_{x}$ with $\mathrm{NH}_{3}$ (Hong He, Res. Center Eco-Environ. Sci., CAS) and the current status and perspectives of rare earth catalysis (Guanzhong Lu, East China Univ. Sci. Technol. (ECUST)). The communication and research articles discussed ceria-modified Pd-only close-coupled cata- lysts (Renxian Zhou, Zhejiang Univ.), the $\mathrm{MnO}_{x}-\mathrm{CeO}_{2}$ SCR catalyst (Xiaodong $\mathrm{Wu}$, Tsinghua Univ.), SCR of $\mathrm{NO}$ with $\mathrm{NH}_{3}$ on Ce-Ti oxides (Zhaoliang Zhang, Jinan Univ.), NO and $\mathrm{C}_{10} \mathrm{H}_{22}$ oxidation and SCR of $\mathrm{NO}$ by $\mathrm{C}_{10} \mathrm{H}_{22}$ over $\mathrm{La}(\mathrm{Sr}, \mathrm{K}) \mathrm{MnO}_{3}$ perovskites (Anne Giroir-Fendler, Univ. Lyon 1), DFT study of the $\mathrm{CO}+\mathrm{NO}_{x}$ reaction over a $\mathrm{Au} / \mathrm{CeO}_{2}(110)$ catalyst (Xueqing Gong, ECUST), NMR and DFT studies of the acidity of rare earth exchanged $Y$ zeolites (Shanqing Yu, Res. Inst. Petrol. Process., SINOPEC), oxidative dehydrogenation of ethane over $\mathrm{CeO}_{2}$-based catalysts (Ye Wang, Xiamen Univ.), vanadia catalyzed oxidative dehydrogenation of iso-butane (Zhengping Hao, Res. Center Eco-Environ. Sci., CAS), dry reforming of methane over perovskite catalysts (David Rooney, Queen's Univ. Belfast), influence of the preparation method on the catalytic property of $\mathrm{CuO} / \mathrm{CeO}_{2}$ for $\mathrm{CO}$ oxidation (Lin Dong, Nanjing Univ.), $\mathrm{Cu}-\mathrm{K}-\mathrm{La} / \gamma-\mathrm{Al}_{2} \mathrm{O}_{3}$ catalyst for $\mathrm{HCl}$ oxidation (Yanglong Guo, ECUST), redox property of and $\mathrm{CO}_{2}$ capture of $\mathrm{CeO}_{2}$ (Yanqin Wang, ECUST), Gd-doped ceria barrier layer for anode-supported SOFCs (Mojie Cheng, Dalian Inst. Chem. Phy., CAS), and 180 study of peroxide species on cubic $\mathrm{Nd}_{2} \mathrm{O}_{3}$ (Weizheng Weng, Xiamen Univ.).

We are grateful to all the authors for contributing their high quality manuscripts, and also thank the staff in the editorial office to carefully and thoroughly work for this special issue. We hope more excellent research results will be published in Chinese Journal of Catalysis as a result of this special issue.

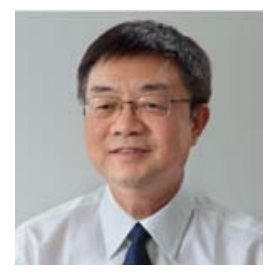

Guanzhong Lu (卢冠忠) Key Laboratory for Advanced Materials Research Institute of Industrial Catalysis East China University of Science and Technology Shanghai 200237, China E-mail address: gzhlu@ecust.edu.cn 